\title{
Clinical Study \\ Influence of First-Time Mothers' Early Employment on Severe Early Childhood Caries in Their Child
}

\author{
Kamila Plutzer' ${ }^{1}$ and Marc J. N. C. Keirse ${ }^{2}$ \\ ${ }^{1}$ Australian Research Centre for Population Oral Health, School of Dentistry, The University of Adelaide, Adelaide, \\ SA 5005, Australia \\ ${ }^{2}$ Department of Obstetrics, Gynaecology and Reproductive Medicine, Flinders Medical Centre, Flinders University, \\ Bedford Park, SA 5042, Australia
}

Correspondence should be addressed to Marc J. N. C. Keirse, marc.keirse@flinders.edu.au

Received 26 June 2012; Revised 12 September 2012; Accepted 12 September 2012

Academic Editor: Lavjay Butani

Copyright ( 2012 K. Plutzer and M. J. N. C. Keirse. This is an open access article distributed under the Creative Commons Attribution License, which permits unrestricted use, distribution, and reproduction in any medium, provided the original work is properly cited.

\begin{abstract}
Aim. To examine whether mothers' early employment status is related to the development of severe early childhood caries in their child. Methods. Questionnaire survey of 429 first-time mothers in metropolitan Adelaide, South Australia, and dental examinations of their child at 20 months of age. Results. At $20 \pm 2.5$ months of age, 5.6\% of children exhibited caries defined as one or more demineralized or cavitated lesions on the upper incisors. Of the mothers, 52.2\% had no paid employment, 39.6\% were part-time and $8.2 \%$ full-time employed. Overall, mothers' participation in the workforce had no influence on the frequency of severe early childhood caries in their child, but there was a significant interaction with family structure. For mothers without employment there was no difference between single, and two-parent families, but children with an employed single mother more frequently had caries than those with a working mother in a two-parent family $(P<0.04)$. However, there were no significant differences in children's reported general health. Conclusions. The data indicate a need to explore strategies that may assist single mothers and especially those in the workforce to prevent severe early childhood caries in their child.
\end{abstract}

\section{Introduction}

Early childhood caries has been on the increase in many countries in recent years and has become a significant public health problem across the globe [1]. The USA National Institutes of Health defined early childhood caries as one or more decayed (cavitated or noncavitated), missing because of caries, or filled primary teeth in a child under 6 years of age [2]. In children younger than 3 years of age, any sign of smooth surface caries (cavitated or not) is considered to be severe early childhood caries [2]. Early childhood caries seriously affects a child's well-being, learning ability, and quality of life [3]. It also impacts on the quality of life of its parents [3]. Moreover, early childhood caries has consequences even after the primary teeth have exfoliated. It is known to be the most powerful predictor of caries in the subsequent permanent teeth $[4,5]$ with all its ill effects, financial, and otherwise for the individual and the health-care system.
A review of epidemiological data since 2000 in a range of low-, middle- and high-income countries, indicated a marked increase in the prevalence of caries in both the deciduous and permanent dentitions of young children [1]. In the 1990s, the prevalence of severe early childhood caries in 2-3 years old children in South Australia was already $16.7 \%$ [6]. In Australia as a whole, the mean dmft (the average sum of decayed, missing due to caries, and filled teeth) at 4 years of age, the youngest group for which oral health data are available, increased from 1.1 in 1997 to 1.7 in 2004. In 2004, 38 percent of 4-year-old children had at least one tooth decayed, filled, or absent due to caries [7]. For some time now, early childhood caries has been the main reason for hospitalization of children aged 4 years or less in Australia [8], nearly all of whom require general anesthesia to address the problem.

No single factor has been identified to be responsible for the increased prevalence of early childhood caries, which 
is an infectious and communicable disease that originates from an interaction among several biological, behavioral, and social determinants. Traditionally, research in this area has focused mainly on biological and dietary factors. In recent years, the focus has broadened. Social, economic, and environmental factors are now recognized to be significant contributors to the development of the disease. This applies in Australia too where the prevalence of early childhood caries is substantially higher in rural than in metropolitan areas [9] and especially high in its Aboriginal population [10].

Many studies have indicated that early childhood caries is largely preventable by good oral hygiene of mothers and children and proper eating habits instituted by mothers early on [11-15]. However, mothers of young children have several competing tasks. Not the least of these is joining the workforce to support the family budget, to advance or resume their professional career or for any other reasons. We found that providing mothers with information on caries prevention reduced the frequency of severe early childhood caries fivefold from $9.6 \%$ to $1.7 \%$ [12]. In absolute, but not in relative, terms the effect was greater in children from oneparent families than in those from two-parent families [16]. We, therefore, sought to examine whether mothers' early return to work would have an influence on the development of severe early childhood caries in their child compared with stay-at-home mothers.

\section{Methods}

Data for this study were derived from a randomized controlled trial which enrolled 649 pregnant women expecting their first child in an oral health promotion intervention programme "Cavity-free children" with the aim of reducing the prevalence of early childhood caries at 1.5 years of age [12]. They were enrolled during routine antenatal visits at all 5 public maternity hospitals in metropolitan Adelaide and represented 20 percent of all women with a first singleton pregnancy in public hospitals in Adelaide, South Australia. Details of the trial have been published previously [12]. Women in the intervention group received three rounds of printed information on oral health maintenance, emphasising the importance of mothers' practices, and the specific health needs of their child at that particular stage of its development (obtainable from the authors). The first round, focusing on mothers' oral health, was provided at enrolment in the study, the second when the child was 6 months old, and the third when the child was 12 months old. The latest two sets were mailed to the home address. There was no interaction with the control group between enrolment and the outcome assessment at 20 months.

Twenty-five mothers were excluded due to the absence of a mother-infant pair at followup or a congenital abnormality in the child, and 441 brought their child for an assessment of their child's dental status at $20 \pm 2.5$ (SD) months of age. Of these mothers, 429 had completed a questionnaire providing demographic details on their employment status, family structure (single, or two-parent family), and level of education. Levels of education were defined on the basis of the highest diploma or certificate obtained. Thus, mothers with incomplete secondary education were classified as having completed only primary education, and mothers with only some higher education were classified as having completed only secondary education.

Questionnaires were completed by mothers in the privacy of their home before attending the examination. Mothers also answered questions about their child's general health and whether the child had ever been hospitalized after being taken home after birth. We did not explore the reasons why mothers entered or reentered the workforce after giving birth or why they had not done so.

All dental examinations were conducted by the same dentist who had been independently calibrated in the conduct of these examinations, and was blinded to the mothers' characteristics. Children were examined sitting on their mother's lap following a standard protocol for the dental examination of young children [12]. The study focused on the earliest manifestation of severe early childhood caries, defining it as the presence of any cavitated or non cavitated lesions on the upper incisors, which are readily visible without the use of sharp instruments.

Statistical analyses including chi-square tests for categorical variables and logistic regression analyses were conducted with PASW Statistics 18.

Approval for the study was obtained from the ethics committees at all 5 hospitals where women were recruited and from the Human Research Ethics Committee at the University of Adelaide. All mothers signed informed consent.

\section{Results}

Demographic characteristics of the mothers in the study are shown in Table 1. Their age distribution mimicked that of all mothers giving birth to a first child in South Australia. At the time of the examination of their child at $20 \pm 2.5$ months of age, $47.8 \%$ were either self-employed or in paid employment, but only $17 \%$ of them full time. Their age distribution was similar to that of stay-at-home mothers, but they were more likely to be part of a two-parent family $(85.3 \%$ versus $76.2 \%$; $P<0.03)$, and to have completed tertiary education $(32.1 \%$ versus $10.5 \% ; P<0.02)$ than stay-at-home mothers.

Table 2 shows that a third of working mothers (32.7\%) resumed work within 6 months after giving birth, but only $8 \%$ did so within the first 3 months, with no difference between those in part-time or full-time occupations. About 60 percent relied on a grandparent, mostly the grandmother, and 38 percent relied on the child's father to look after their child during their absence (Table 3). Forty percent of working mothers relied on at least two child carers (Table 3 ).

Mothers' opinions on the general health of their child and whether the child had ever been hospitalized after being taken home after birth are shown in Table 4. Twenty-eight percent of children had spent at least one day in hospital for one reason or another after having left hospital as a neonate. None of them were reported to be currently in ill health, though. Table 4 also shows the frequency of early 
TABLE 1: Characteristics of mothers in the study.

\begin{tabular}{|c|c|c|c|c|c|c|}
\hline \multirow{2}{*}{ Mothers' characteristics } & \multicolumn{2}{|c|}{ Employed } & \multicolumn{2}{|c|}{ Unemployed } & \multicolumn{2}{|c|}{ Total } \\
\hline & No. & $\%$ & No. & $\%$ & No. & $\%$ \\
\hline Employment status & & & & & 429 & 100.0 \\
\hline Full time & 35 & 17.1 & 0 & - & 35 & 8.2 \\
\hline Part time & 170 & 82.9 & 0 & 一 & 170 & 34.6 \\
\hline Unemployed & 0 & - & 224 & 100.0 & 224 & 52.2 \\
\hline \multicolumn{7}{|c|}{ Maternal age at childbirth (years) } \\
\hline Under 25 & 80 & 39.0 & 106 & 47.3 & 186 & 43.4 \\
\hline $25-29$ & 73 & 35.6 & 68 & 30.4 & 141 & 32.9 \\
\hline $30-45$ & 52 & 25.4 & 50 & 22.3 & 102 & 23.8 \\
\hline \multicolumn{7}{|c|}{ Mother's highest completed education } \\
\hline Primary & 55 & 28.1 & 83 & 37.9 & 138 & $33.3^{*}$ \\
\hline Secondary & 78 & 39.8 & 91 & 41.6 & 169 & $40.7^{*}$ \\
\hline Tertiary & 63 & 32.1 & 45 & 10.5 & 108 & $26.0^{*}$ \\
\hline Not disclosed & 9 & & 5 & & 14 & \\
\hline \multicolumn{7}{|l|}{ Family status } \\
\hline Single parent & 29 & 14.7 & 50 & 23.8 & 79 & $19.4^{* *}$ \\
\hline Two parents & 168 & 85.3 & 160 & 76.2 & 328 & $80.6^{* *}$ \\
\hline Not disclosed & 8 & & 14 & & 22 & \\
\hline
\end{tabular}

${ }^{*} P<0.02 ;{ }^{*} P<0.03$.

TABLE 2: Timing of mothers' return to the workforce.

\begin{tabular}{|c|c|c|c|c|c|c|}
\hline \multirow{2}{*}{ Child's age at mother's return to work } & \multicolumn{2}{|c|}{ Full time } & \multicolumn{2}{|c|}{ Part time } & \multicolumn{2}{|c|}{ Total } \\
\hline & No. & $\%$ & No. & $\%$ & No. & $\%$ \\
\hline Less or equal to 3 months & 2 & 5.8 & 15 & 8.8 & 17 & 8.3 \\
\hline Between 3 and 6 months & 12 & 34.3 & 38 & 22.4 & 50 & 24.4 \\
\hline After 6 months up to 1 year & 18 & 51.4 & 94 & 55.3 & 112 & 54.6 \\
\hline From 1 to 2 years & 3 & 8.5 & 23 & 13.5 & 26 & 12.7 \\
\hline Total & 35 & 100.0 & 170 & 100.0 & 205 & 100 \\
\hline
\end{tabular}

TABLE 3: Usual carer for the child during mother's absence at work* .

\begin{tabular}{lccc}
\hline Usual carer & Number & Percent of children* & Percent of carers* \\
\hline Grandmother & 107 & 52.2 & 37.8 \\
Father & 77 & 37.6 & 26.0 \\
Child care centre & 53 & 25.9 & 17.9 \\
Grandfather & 24 & 11.7 & 8.1 \\
Family child care** & 14 & 6.8 & 4.7 \\
Other family member & 11 & 5.4 & 3.7 \\
Other & 10 & 4.9 & 3.4 \\
\hline Total & 296 & $-*$ & 100.0 \\
\hline
\end{tabular}

* Of the 205 children, 123 (60\%) had one usual carer, 67 (32.7\%) had two carers and 15 (7.3\%) had three. **Family child care refers to a child cared for by a foster mother in her home. 
TABLE 4: Characteristics of the children.

\begin{tabular}{|c|c|c|c|c|c|c|}
\hline \multirow{2}{*}{$\begin{array}{l}\text { Mothers' employment* } \\
\text { Child's characteristics* }\end{array}$} & \multicolumn{2}{|c|}{ Employed } & \multicolumn{2}{|c|}{ Unemployed } & \multicolumn{2}{|c|}{ Total } \\
\hline & No. & $\%$ & No. & $\%$ & No. & $\%$ \\
\hline \multicolumn{7}{|l|}{ Gender } \\
\hline Male & 105 & 51.2 & 115 & 51.3 & 220 & 51.3 \\
\hline Female & 100 & 48.8 & 109 & 48.7 & 209 & 48.7 \\
\hline \multicolumn{7}{|c|}{ Hospitalized since discharge from hospital } \\
\hline No & 145 & 74.0 & 156 & 70.6 & 301 & 72.2 \\
\hline Yes & 51 & 26.0 & 65 & 29.4 & 116 & 27.8 \\
\hline Not disclosed & 9 & & 3 & & 12 & \\
\hline \multicolumn{7}{|c|}{ General health as reported by mother } \\
\hline Excellent & 99 & 48.3 & 120 & 53.8 & 219 & 51.2 \\
\hline Very good & 84 & 41.0 & 70 & 31.4 & 154 & 36.0 \\
\hline Good & 22 & 10.7 & 33 & 14.8 & 55 & 12.9 \\
\hline Not disclosed & 0 & & 1 & & 1 & \\
\hline \multicolumn{7}{|c|}{ Caries on dental examination } \\
\hline No & 194 & 94.6 & 211 & 94.2 & 405 & 94.4 \\
\hline Yes & 11 & 5.4 & 13 & 5.8 & 24 & 5.6 \\
\hline
\end{tabular}

*None of the data show a statistically significant difference between mothers' employment status.

TABLE 5: Effect of various factors on the prevalence of severe early childhood caries at $20 \pm 2.5$ months of age in univariable and multivariable logistic regression analyses*.

\begin{tabular}{|c|c|c|c|c|}
\hline \multirow{2}{*}{ Variable } & \multicolumn{2}{|c|}{ Univariable analysis } & \multicolumn{2}{|c|}{ Multivariable analysis* } \\
\hline & OR & $95 \% \mathrm{CI}^{* *}$ & OR & $95 \% \mathrm{CI}^{* *}$ \\
\hline \multicolumn{5}{|l|}{ Child's gender } \\
\hline Male & \multicolumn{2}{|c|}{ reference } & \multicolumn{2}{|c|}{ reference } \\
\hline Female & 0.45 & $0.19-1.11$ & 0.48 & $0.19-1.18$ \\
\hline Age at dental exam (months) & 1.18 & $1.03-1.36^{\dagger}$ & 1.20 & $1.02-1.37^{\dagger}$ \\
\hline \multicolumn{5}{|l|}{ Family structure } \\
\hline One parent & \multicolumn{2}{|c|}{ reference } & \multicolumn{2}{|c|}{ reference } \\
\hline Two parents & 0.37 & $0.16-0.88^{\dagger}$ & 0.37 & $0.14-0.93^{\dagger}$ \\
\hline \multicolumn{5}{|c|}{ Mother's age at childbirth in years } \\
\hline Under 25 & \multicolumn{2}{|c|}{ reference } & \multicolumn{2}{|c|}{ reference } \\
\hline 25 to 29 & 0.84 & $0.32-2.24$ & 0.84 & $0.27-2.65$ \\
\hline 30 to 45 & 0.59 & $0.19-1.84$ & 0.55 & $0.17-1.75$ \\
\hline \multicolumn{5}{|c|}{ Mother's highest level of education } \\
\hline Primary & \multicolumn{2}{|c|}{ reference } & \multicolumn{2}{|c|}{ reference } \\
\hline Secondary & 0.66 & $0.22-2.04$ & 0.47 & $0.12-1.81$ \\
\hline Tertiary & 0.89 & $0.33-2.48$ & 0.87 & $0.29-2.57$ \\
\hline \multicolumn{5}{|l|}{ Mother's' employment } \\
\hline Employed & \multicolumn{2}{|c|}{ reference } & \multicolumn{2}{|c|}{ reference } \\
\hline Unemployed & 1.09 & $0.47-2.48$ & 0.97 & $0.41-2.30$ \\
\hline
\end{tabular}

childhood dental caries at $20 \pm 2.5$ months of age. Just over 1 in $20(5.6 \%)$ showed signs of severe early childhood caries at this early age. However, none of the indices of child health differed between the children of employed and stay-at-home mothers (Table 4). There was a significant interaction, though, with family structure. For mothers without employment, there was no difference between single, and two-parent families, but children with a working single mother more frequently exhibited caries than those with a working mother in a two parent family $(P<0.04)$.

Logistic regression analysis, shown in Table 5, indicates that, at this early age, caries prevalence increased with about $20 \%$ for each extra month of age. It also indicates that, on its own, mothers' employment or early return to work had little 
influence on the development of early childhood caries in their child (Table 5). Having only one parent or two parents seems to be of much greater importance.

\section{Discussion}

Mothers are the gatekeepers to the health and healthy behaviors of their children [17-19]. However, mothers' role in society has changed drastically from the traditional model of caring for children and looking after their husband's needs. Currently, women comprise 46 percent of the workforce in Australia with 54 percent of them working full time. In 1979, when maternity leave, unpaid at the time, was introduced in Australia, few mothers returned to work before their child reached school age. In 2011, 35 percent of mothers had returned to work by the time their child reached one year of age and 50 percent were back at work by the time the child was 2 years old. Paid maternity leave was only introduced in Australia in 2011 and still applies only to the public sector, although private companies are increasingly providing paid maternity leave in order to attract staff, maintain an experienced workforce, and offset the costs of training new employees. Over that period, family structure changed too. In the 2006 Australian census, 22 percent of families were single-parent families (Australian Bureau of Statistics, available on http://www.abs.gov.au/AUSSTATS) roughly similar to that seen in our study population.

In our randomized controlled trial of providing new mothers with comprehensive guidance on preventing early childhood caries, we found that the benefits of the intervention were much greater in absolute terms for children in single-parent families than in two-parent families. This was not so in terms of relative risk reduction, though. The intervention reduced the frequency of early childhood caries only 3.5 -fold (from $16.3 \%$ to $4.5 \%$ ) in single-mother families compared with 7 -fold (from $8.1 \%$ to $1.1 \%$ ) in two-parent families [16].

Although we had anticipated that mothers' early return to work would have an influence on the development of early childhood caries in their child, there was no evidence to that effect. The only effect that was sustained in univariable and multivariable analyses was single parenthood. Obviously, single mothers do not fit into one category. Some may have been divorced, separated, widowed, or single by choice. Nonetheless, our data seem to indicate that single mothers are less effective in maintaining the oral health of their child than other mothers, especially if they also have occupational obligations. By itself, mothers' return to work does not seem to be an issue in our community, but there is much to be said for providing extra support to mothers and children living in a single-parent family or at least to explore how their relative disadvantage can be counteracted. After all, what applies to severe early childhood caries may apply to other health issues too.

\section{Acknowledgment}

This study was supported by NHMRC Centre of Clinical Research Excellence, Adelaide, South Australia.

\section{References}

[1] R. A. Bagramian, F. Garcia-Godoy, and A. R. Volpe, "The global increase in dental caries. A pending public health crisis," American Journal of Dentistry, vol. 22, no. 1, pp. 3-8, 2009.

[2] T. F. Drury, A. M. Horowitz, A. I. Ismail, M. P. Maertens, R. G. Rozier, and R. H. Selwitz, "Diagnosing and reporting early childhood caries for research purposes. A report of a workshop by the NCDR," Journal of Public Health Dentistry, vol. 59, no. 3, pp. 192-197, 1999.

[3] J. Abanto, T. S. Carvalho, F. M. Mendes, M. T. Wanderley, M. Bönecker, and D. P. Raggio, "Impact of oral diseases and disorders on oral health-related quality of life of preschool children," Community Dentistry and Oral Epidemiology, vol. 39, no. 2, pp. 105-114, 2011.

[4] H. S. Horowitz, "Research issues in early childhood caries," Community Dentistry and Oral Epidemiology, vol. 26, no. 1, supplement, pp. 67-81, 1998.

[5] B. Peretz, D. Ram, E. Azo, and Y. Efrat, "Preschool caries as an indicator of future caries: a longitudinal study," Pediatric Dentistry, vol. 25, no. 2, pp. 114-118, 2003.

[6] A. H. . Wyne, "Prevalence and risk factors of nursing caries in Adelaide, South Australia," Pediatric Dentistry Journal, vol. 9, no. 1, pp. 31-36, 1999.

[7] J. M. Armfield, A. J. Spencer, and D. S. Brennan, Dental Health of Australia's Teenagers and Pre-Teen Children: The Child Dental Health Survey, Australia 2003-04, vol. 52 of Dental Statistics and Research Series, Cat no. DEN 199, AIHW, Canberra, Australia, 2009.

[8] Australian Institute of Health and Welfare, Australian Hospital Statistics 2003-2004, vol. 23 of Health Services Series, Cat. no. HSE 37, AIHW, Canberra, Australia, 2005.

[9] Department of Human Services, The Victorian Ambulatory Care Sensitive Conditions Study, 2001-02. Melbourne, Public Health Division, Department of Human Services, Victoria, Australia, 2004.

[10] L. M. Jamieson, J. M. Armfield, and K. F. Roberts-Thomson, Oral Health of Aboriginal and Torres Strait Islander Children., vol. 35 of Dental Statistics and Research Series, Cat. no. DEN 167, AIHW, Canberra, Australia, 2007.

[11] S. A. Fisher-Owens, S. A. Gansky, L. J. Platt et al., "Influences on children's oral health: a conceptual model," Pediatrics, vol. 120, no. 3, pp. e510-e520, 2007.

[12] K. Plutzer and A. J. Spencer, "Efficacy of an oral health promotion intervention in the prevention of early childhood caries," Community Dentistry and Oral Epidemiology, vol. 36, no. 4, pp. 335-346, 2008.

[13] M. B. Kowash, A. Pinfield, J. Smith, and M. E. J. Curzon, "Effectiveness on oral health of a long-term health education programme for mothers with young children," British Dental Journal, vol. 188, no. 4, pp. 201-205, 2000.

[14] H. Günay, K. Dmoch-Bockhorn, Y. Günay, and W. Geurtsen, "Effect on caries experience of a long-term preventive program for mothers and children starting during pregnancy," Clinical Oral Investigations, vol. 2, no. 3, pp. 137-142, 1998.

[15] S. Twetman, "Prevention of early childhood caries (ECC) review of literature published 1998-2007," European Archives of Paediatric Dentistry, vol. 9, no. 1, pp. 12-18, 2008.

[16] K. Plutzer and M. J. N. C. Keirse, "Incidence and prevention of early childhood caries in one- and two-parent families," Child: Care, Health and Development, vol. 37, no. 1, pp. 5-10, 2011.

[17] T. L. Finlayson, K. Siefert, A. I. Ismail, and W. Sohn, "Maternal self-efficacy and 1-5-year-old children's brushing habits," 
Community Dentistry and Oral Epidemiology, vol. 35, no. 4, pp. 272-281, 2007.

[18] P. Paunio, P. Rautava, H. Helenius, and M. Sillanpää, "Children's poor toothbrushing behavior and mothers' assessment of dental health education at well-baby clinics," Acta Odontologica Scandinavica, vol. 52, no. 1, pp. 36-42, 1994.

[19] Z. Saied-Moallemi, J. I. Virtanen, F. Ghofranipour, and H. Murtomaa, "Influence of mothers' oral health knowledge and attitudes on their children's dental health," European Archives of Paediatric Dentistry, vol. 9, no. 2, pp. 79-83, 2008. 


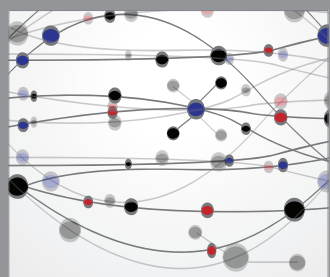

The Scientific World Journal
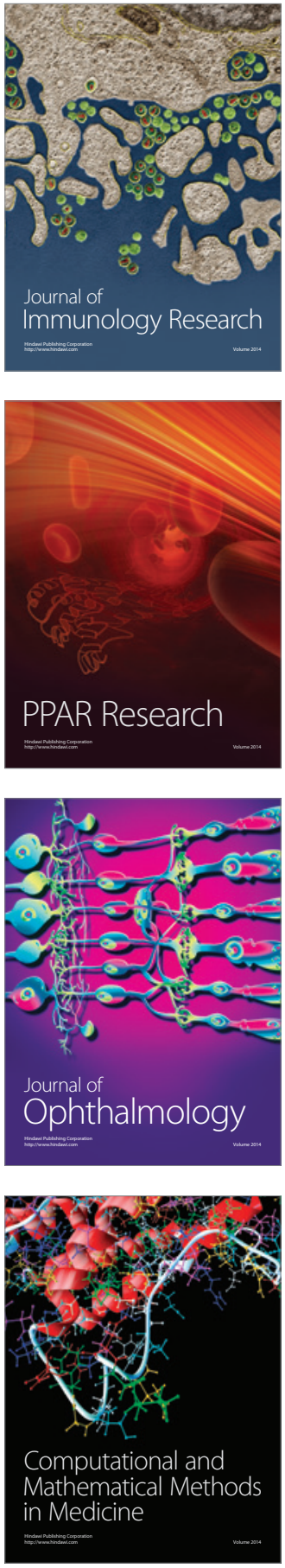

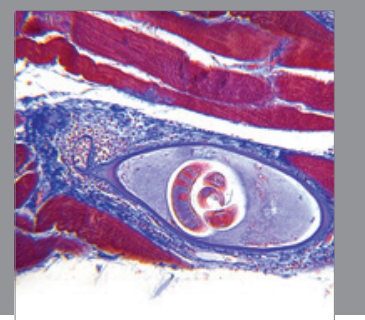

Gastroenterology

Research and Practice
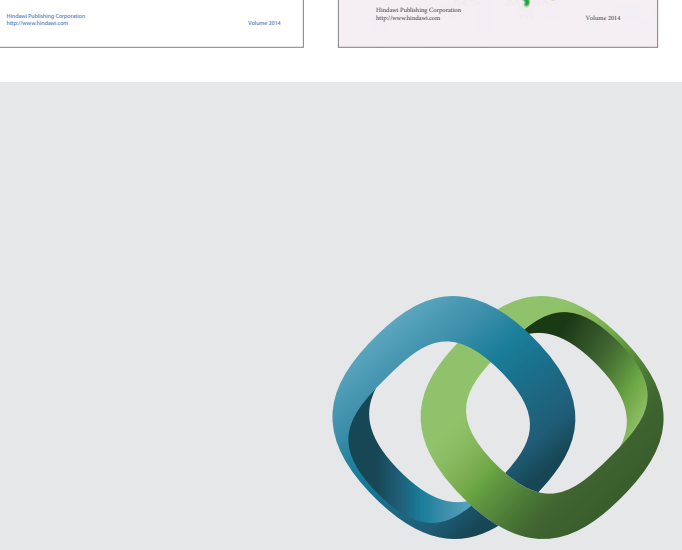

\section{Hindawi}

Submit your manuscripts at

http://www.hindawi.com
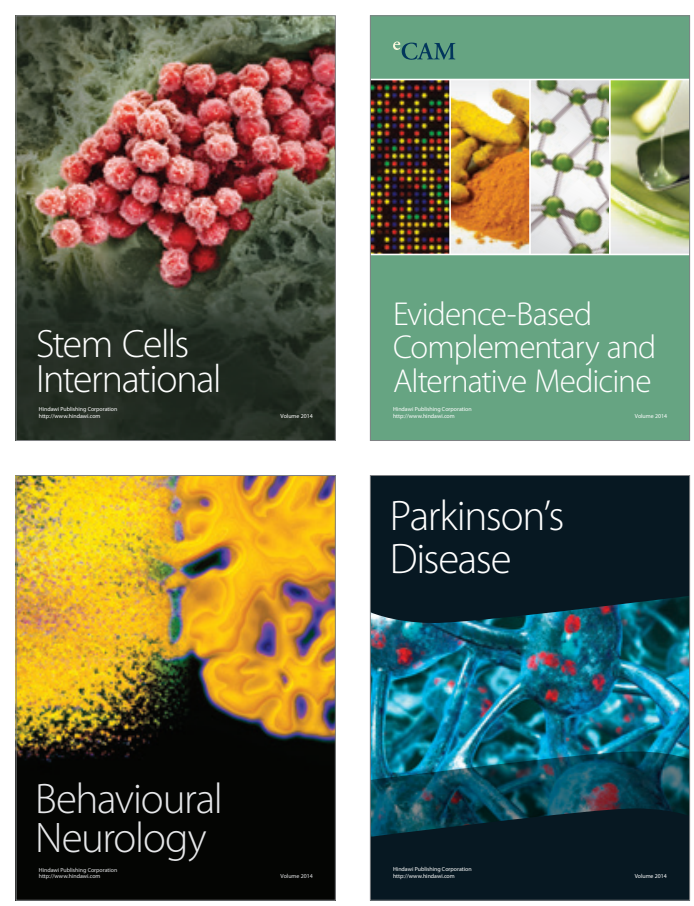

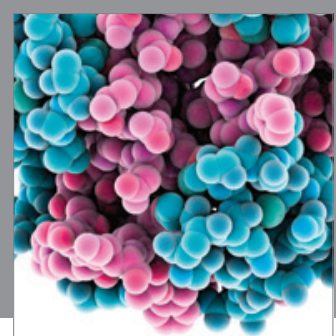

Journal of
Diabetes Research

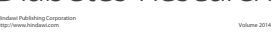

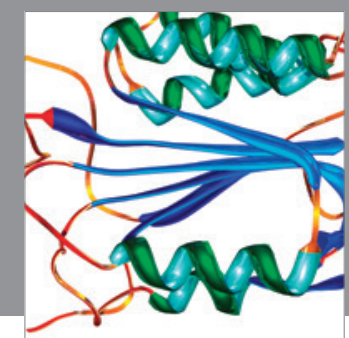

Disease Markers
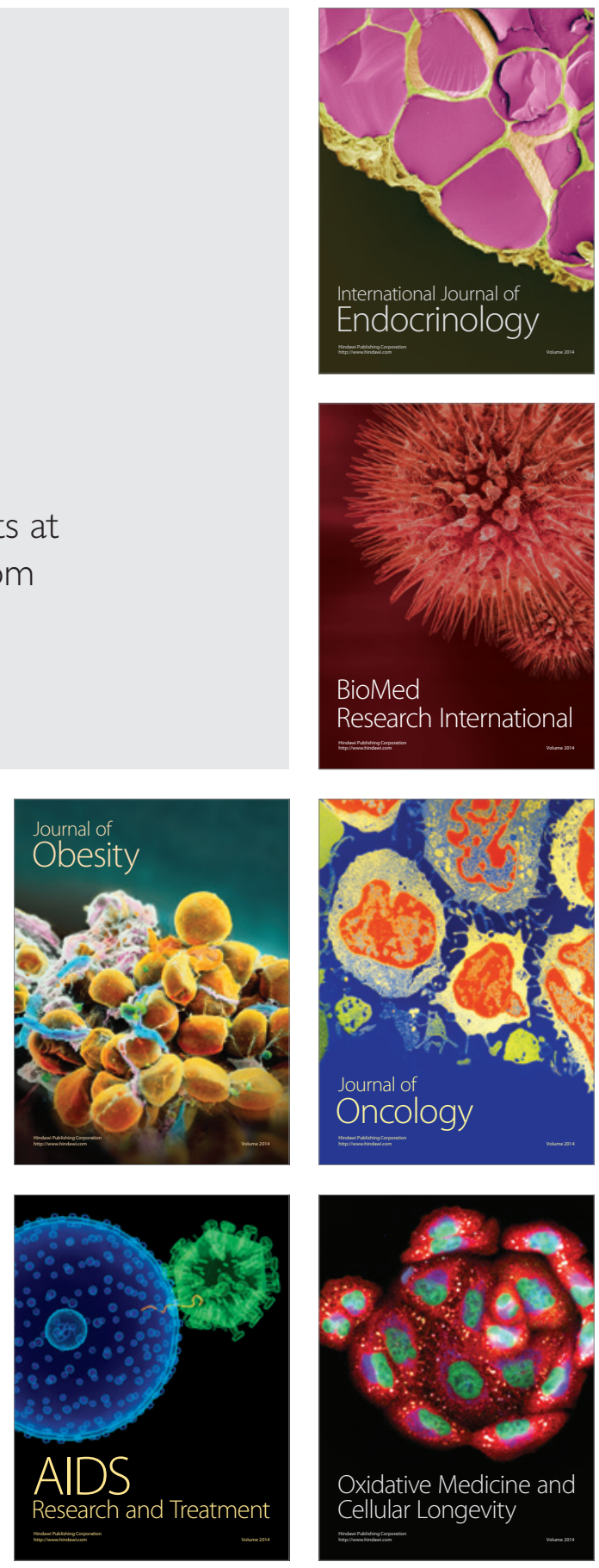